\title{
Evaluation of the Teaching Performance of University Lecturers: Comparison between Mexico and Spain
}

\author{
Matilde Diaz ${ }^{1, *}$, Africa Borges ${ }^{2}$, Dolores Valadez ${ }^{3} \&$ Rogelio Zambrano ${ }^{4}$ \\ ${ }^{1}$ DEPT. Psicología Cognitiva, Social y Organizacional, Universidad de La Laguna, Campus de Guajara, s/n, Tenerife, \\ Spain \\ ${ }^{2}$ DEPT. Psicología Clínica, Psicobiología y Metodología, Universidad de La Laguna, Campus de Guajara, s/n, \\ Tenerife, Spain \\ ${ }^{3}$ DEPT. Psicología Aplicada, Centro Universitario Ciencias de La Salud, Universidad de Guadalajara, Jalisco, \\ Mexico \\ ${ }^{4}$ Secretaría Académica, Centro Universitario Ciencias de La Salud, Universidad de Guadalajara, Jalisco, Mexico \\ *Correspondence: DEPT. Psicología Clínica, Psicobiología y Metodología, Universidad de La Laguna, Campus de \\ Guajara, s/n, Tenerife, Spain. Tel: 34-922-7568. E-mail: aborges@ull.edu.es
}

Received: June 17, $2015 \quad$ Accepted: August 1, $2015 \quad$ Online Published: August 24, 2015

doi:10.5430/jct.v4n2p53 URL: http://dx.doi.org/10.5430/jct.v4n2p53

\begin{abstract}
Comparative educational studies allow the study of the differences and similarities between different educational systems. This research, which consists on an educational evaluation, has studied the teaching behavior of ten university lecturers from a Spanish university -the University of La Laguna-, and seven from a Mexican university -University of Guadalajara-, laying the foundation in the Teaching Functions Model. It has been made through the observational methodology and by registering their real conduct while teaching. The observational instrument, PROFUNDO_Uni, v3, was adapted for its implementation in both universities. Before developing the coding of the behaviors, we trained ten Spanish lecturers and eight from Mexico. Data was analyzed using the sequential lag analysis. The displayed results show a great similarity between the behavioral patterns developed by both groups of lecturers with their students.
\end{abstract}

Keywords: teaching evaluation; university; observational methodology; comparative international studies

\section{Introduction}

The educational system depends on the society where it is embedded. There exists a variety of internal and external factors that determine and define the educational system, adopting those characteristics and values that reflect the society to which it belongs. The use of a comparative perspective allows us to know the reality of education and the particularities of the institutions (Casanova, 1999), supporting the countries in the assessment of their own educational systems from an inter cultural and international perspective (Dede and Baskan 2011).

The changes within the educational system of different countries have developed new models of institutional and teaching management, as well as mechanisms to evaluate the teachers' performance. The interest in their quality has increased contributing to the improvement of the teachers.

There is a wide change in the research, focused on comparing educational systems among countries. Several studies have pointed out the absence of differences in the teaching of teachers between Great Britain and Canada (Young, Hall and Clarke, 2007), Turkey, Great Britain, Germany and France (Kilimci, 2009) or Great Britain and South Africa (Harber and Serf, 2006).

Due to the relevance of the teachers evaluation, one of the main aspects in the assessment of educational quality (Mateo and Martínez, 2008; Martínez, 2013), the comparison between successful educational processes is interesting. Vaillant (2008) focused on the USA, Australia, Chile and Colombia, proving that while in the USA the systems depend on each state, in Australia the process establishes a revision and the planning between the teacher and de assessor. In Chile, teachers' evaluation is educational, based in the improvement of the teaching activity, while in Colombia the evaluation system focuses on different moments of the teachers career, initial, yearly, and based on 
competencies.

The teaching evaluation is multimodal, because it is based on several data sources (Vasquez-Rizo and Galabán-Coello, 2012) in order to gather different aspects to be developed in the teaching-learning process: The education efficiency, the teacher's performance, certification and educational training, the given subject and the individual manner of each teacher (Kember and Leung 2011), which requires us to obtain data from the standardized evidences by evaluating the teachers' knowledge, surveying the teachers and the students, observing the classroom as well as the portfolio and the teacher's estimation in terms of the students' performance (Martínez, 2013).

The observational methodology to evaluate the behaviors has gained importance in the development of observational measures within the classroom (Cameron, Connor and Morrison, 2005; Good, Mulryan and McCaslin, 2006).

The aim of this work is to analyze the lecturers' performance in Mexico and Spain, contributing to the evaluating procedures through systematic observation.

The Spanish university system counts with Degrees, Master's Degrees and Doctorates, while the university studies in Mexico are divided into Senior Technician University Level, Bachelor's Degree and Postgraduate Studies. The way of teaching is also different. In Spain, classes can be theoretical or practical, whereas in Mexico they are integrated within the contents. However, both countries are highly committed with quality through several specialized agencies.

\section{Method}

\subsection{Participating}

We selected an intentional sampling of ten lecturers from the University of La Laguna, two from each of the knowledge branches (Architecture and Engineering, Arts and Humanities, Sciences, Legal and Social Sciences, Health Sciences), lecturers from different subjects, (basic subjects, compulsory and elective) and seven lecturers from the Degree in Psychology at Guadalajara (UdG), Mexico.

\subsection{Instruments}

\subsubsection{Observational Instrument}

We used the Observational Protocol of Teaching Functions at the University (PROFUNDO_Uni, v3; Rodriguez, Cadenas and Díaz, 2011; Díaz, 2014), adapted from PROFUNDO, v2 (Rodríguez-Naveiras, 2011), based on the Teaching Functions Model of Hernández-Jorge (2005). In table number 1, we show the different functions with their definitions, their observable codes and the abbreviation of the codifying process. The instrumental category completes the teacher's behavioral flow. It gathers those behaviors which do not correspond to the lecturers' functions (Other behaviors, X), conducts that the teacher performs off camera (Unobservable Conduct, Y) and when he/she is absent (Teacher leaves the classroom, Z) (Rodríguez, Cadenas and Díaz, 2011).

\subsubsection{Registration Instruments}

The sessions were filmed in the University of La Laguna using two video cameras, SONY DCR-SR58E and JVC GZ MG750. At the University of Guadalajara we used a SONY HDR CX100 Handycam.

\subsection{Procedure}

Participant lecturers and their students signed an informed consent allowing us for their filming in video, agreeing with the normative in terms of data protection for both countries.

Before coding the data, we trained two observers, according to a standardize procedure (Cadenas, Rodríguez and Díaz, 2012; Rodríguez-Naveiras, 2011). There were ten observers at the ULL, nine women and a man. The range of ages was between 23 and 40 years old. There were eight at the UdG, six women and two men between 22 and 34 years old. Their qualifications were a Master's Degree or Bachelor's Degree in Psychology or Primary School Education. There were also Master's students as well as students from Psychology and Speech Therapy.

For each of the lecturers we filmed between 10 and 12 teaching hours. In the case of the ULL lecturers, we also registered practical lessons in the laboratories or classrooms assigned for it.

We chose six sessions of one hour for their coding, calculating the needed sessions in order to obtain a reliability higher to 0,90, following the procedure of Blanco, Castellano and Hernández Mendo (2000). It was determined with the Theory of Generalizability (Cronbach, Gleser, Nanda and Rajaratman, 1972). Due to their possible reactivity, the first filmed sessions were removed, and the rest were chosen in terms of their observational clarity.

The coding instrument used at the ULL was the software AUGEN v. $\delta$ (Montero, J., Montero, J. Computer Business 
Solutions, 2012), elaborated for the development of this research. In the UdG, due to technical difficulties while assessing the program, we opted for a traditional coding using paper and pencil.

Table 1. Observational Protocol in the Teaching Functions at the University (PROFUNDO_UNI), version 3

\begin{tabular}{|c|c|c|}
\hline Teaching functions. & COCES & \\
\hline $\begin{array}{l}\text { ORGANIZATION Context structure: Disposition of educational } \\
\text { resources, establishing the rules, determining the deadline for the } \\
\text { homework, etc. }\end{array}$ & $\begin{array}{l}\text { Academic Planning. } \\
\text { of the context } \\
\text { of the students }\end{array}$ & $\begin{array}{l}\text { AP } \\
\text { OC } \\
\text { OS }\end{array}$ \\
\hline $\begin{array}{l}\text { TEACHING COMMUNICABILITY Explaining the contents in a way } \\
\text { that the students understand. }\end{array}$ & $\begin{array}{l}\text { Teacher's Explanation } \\
\text { Answers the Student }\end{array}$ & $\begin{array}{l}\text { TE } \\
\text { AS }\end{array}$ \\
\hline ENCOURAGING: Encouraging the learning of the student & $\begin{array}{l}\text { Reinforcement } \\
\text { Involvement Encouragement }\end{array}$ & $\begin{array}{l}\text { RF } \\
\text { IE }\end{array}$ \\
\hline $\begin{array}{l}\text { BEHAVIOURAL CONTROL OR ADJUSTMENT OF THE } \\
\text { GROUP: Management of the classroom. }\end{array}$ & Negative Possibility & NP \\
\hline $\begin{array}{l}\text { GUIDANCE AND ADVISING: Guideline for the development of the } \\
\text { students' homework. }\end{array}$ & $\begin{array}{l}\text { Guidance } \\
\text { Non-verbal Revision }\end{array}$ & $\begin{array}{l}\text { GU } \\
\text { NR }\end{array}$ \\
\hline $\begin{array}{l}\text { STUDENTS INTERACTION: Students interventions by own initiative } \\
\text { or by answering the teacher. }\end{array}$ & $\begin{array}{l}\text { Students Participation. } \\
\text { Answers the teacher }\end{array}$ & $\begin{array}{l}\text { SP } \\
\text { AT }\end{array}$ \\
\hline $\begin{array}{l}\text { DISRUPTIVE INTERACTION: Students behavior that stop the } \\
\text { development of the class. }\end{array}$ & Students' disruptions. & SD \\
\hline $\begin{array}{l}\text { GENERAL INTERACTIONS: Comments related to other contents of } \\
\text { the class. }\end{array}$ & $\begin{array}{l}\text { I. General comments from } \\
\text { the teacher } \\
\text { II. General comments from } \\
\text { the students }\end{array}$ & GCT \\
\hline INSTRUMENTAL CATEGORIES & $\begin{array}{c}\text { Other behaviors } \\
\text { Unobservable } \\
\text { Teacher leaves the } \\
\text { classroom }\end{array}$ & $\begin{array}{l}\mathbf{X} \\
\mathbf{Y}\end{array}$ \\
\hline
\end{tabular}

\subsection{Statistical Analysis}

Data analysis was carried out using the Generalizability Theory to calculate its reliability and the SDIS-GSEQ, 5.1. (Bakeman and Quera, 1996) for sequential analysis.

\section{Results}

We calculated the reliability between observers with the Generalizability Theory. At the time of ending the training, the obtained coefficient in both universities was 0,98 . In the coding of the sessions there were two reliability sessions following the Patterson criteria (1982): We codified a $20 \%$ of the sessions, obtaining in both cases optimal values (generalizability coefficients in the first session between 0,89 and 1,00 and in the second one between 0,93 and 1,00).

The observational methodology studies one group behavior, which reflects a constant ordered shape in time, highlighting the subject who is the object of this study, in this case the lecturer and the interaction with his/her students. We analyzed the relations of temporary possibilities between conducts, allowing the uncovering of the rules that regulate its internal mechanism. This is where we determine how the occurrence possibilities of the behaviors can change depending on the previous conducts, then capturing patterns of behavior that are statistically relevant.

The procedure that we used is the lag sequential analysis of Bakeman and Quera (1996) which is useful when detecting behavioral patterns (Sackett, 1979) proving if a conduct is followed by another with a higher probability than the expected randomly. We take an antecedent conduct, from what we count the times that other conducts (consequent conducts) follow it in the next order place. For the first lag, we obtained an excitatory dependency, which means it is higher than the expected randomly, when $\mathrm{Z}$ is higher than 1.96 or dismissal if it is lower than -1.96 .

We considered as criteria conduct all those with a relative conduct higher than 0.02 , taking as consequent conduct any one with a frequency higher than zero. The behavior of the lecturer as well as of his/her students is registered. The results presented in the following tables correspond to the obtained patterns in the behavior of the studied lecturers, which take place in the first lag, taking only those excitatory conducts. 
The patterns that correspond to the Organization Function are presented in table number 2. The code Students Organization has been omitted since it has not produced any behavioral pattern.

Table 2. Antecedent Conducts to the Organization Function and Consequent Conducts in First Lag

\begin{tabular}{|c|c|c|c|c|c|c|}
\hline \multirow{4}{*}{ Pr. } & \multicolumn{6}{|c|}{$\begin{array}{l}\text { FUNCTION OF ORGANIZATION } \\
\end{array}$} \\
\hline & \multicolumn{4}{|c|}{ ULL Lecturers } & \multicolumn{2}{|c|}{ UdG Lecturers } \\
\hline & \multicolumn{2}{|c|}{$\mathbf{A P}$} & \multicolumn{2}{|c|}{ OC } & \multirow{2}{*}{ AP } & \multirow{2}{*}{ OC } \\
\hline & Theoretical & Practical & Theoretical & Practical & & \\
\hline 1 & -- & OS & -- & $\mathrm{Y}$ & -- & IE-SP \\
\hline 2 & -- & -- & AP & -- & TE-SP & NR \\
\hline 3 & -- & -- & -- & -- & -- & $\mathrm{NR}-\mathrm{GCT}-\mathrm{Y}$ \\
\hline 4 & -- & $\mathrm{Y}$ & AP & -- & -- & $\mathrm{RF}-\mathrm{Y}$ \\
\hline 5 & -- & -- & -- & $\mathrm{TE}$ & -- & NR \\
\hline 6 & $\mathrm{OC}$ & -- & TE & -- & -- & $\mathrm{NR}-\mathrm{GCT}-\mathrm{Y}$ \\
\hline 7 & $\mathrm{OC}$ & $\mathrm{OC}-\mathrm{NR}$ & SD - Y & $\mathrm{AP}-\mathrm{TE}-\mathrm{NR}$ & -- & $\mathrm{AP}-\mathrm{SD}-\mathrm{Y}$ \\
\hline 8 & -- & OC & -- & TE & & \\
\hline 9 & SP - GCT & -- & TE - Y & $\mathrm{TE}-\mathrm{SP}-\mathrm{Y}$ & & \\
\hline 10 & $\mathrm{TE}-\mathrm{PG}$ & -- & TE - Y & -- & & \\
\hline
\end{tabular}

Note: Academic Planning (AP), of the context (OC), of the students (OS), Teacher's Explanation (TE), Reinforcement (RF), Involvement Encouragement (IE), Non-verbal Revision (NR), Students Participation (SP), Students' disruptions (SD), I. General comments from the teacher (GCT), Unobservable (Y)

We obtained significant patterns from the lecturers of the ULL for antecedent behaviors Academic Planning (PA) and Educational Context Organization (OD), both in theoretical classes as well as practical, but not in all the lecturers and not with the same structure, which means we cannot talk about general patterns in this context.

In the UdG, the significant patterns that are more common appear in the code of Educational Context Organization (OD), which means that all the lecturers participating in the process use this strategy, but the resultant patterns are different in each case. The most common consequent code is Non-Verbal Revision (RN), which appears in four lecturers. Academic Planning (PA) only produces significant patterns in one of the lecturers.

When dealing with the Teaching Communicability Function, shown in table number 3, we present the patterns of behavior that are significant in Teacher's Explanation (TE) taken as antecedent, both for theoretical as well as practical matters and also in both universities. This is followed by two generalized conducts: Involvement Encouragement (IE), which exposes lecturers finding importance in making their students participate in class in order to confirm they understand the explanations, and Students Involvement (SI) which verifies that the students are making an appropriate contribution.

Table 3. Antecedent Conducts to the Teaching Communicability Function and Consequent Conducts in First Lag

\begin{tabular}{|c|c|c|c|c|c|c|}
\hline \multirow[b]{4}{*}{ Pr. } & \multicolumn{6}{|c|}{ TEACHING COMMUNICABILITY FUNCTION } \\
\hline & \multicolumn{4}{|c|}{ ULL Lecturers } & \multicolumn{2}{|c|}{ UdG Lecturers } \\
\hline & \multicolumn{2}{|c|}{ TE } & \multicolumn{2}{|c|}{ AS } & \multirow[t]{2}{*}{ TE } & \multirow[t]{2}{*}{ AS } \\
\hline & Theoretical & Practical & Theoretical & Practical & & \\
\hline 1 & -- & IE - GU & -- & SP & $\mathrm{OC}-\mathrm{IE}-\mathrm{SP}$ & -- \\
\hline 2 & AP - IE & -- & -- & -- & IE - SP & SP \\
\hline 3 & SP -GCT & IE - SP & -- & SP & IE - SP - SD & TE-SP \\
\hline 4 & IE - GCT & $\mathrm{AP}-\mathrm{OC}$ & -- & -- & $\mathrm{OC}-\mathrm{IE}-\mathrm{SP}$ & TE-SP \\
\hline 5 & IE - SP & $\mathrm{OC}-\mathrm{IE}-\mathrm{SP}$ & TE-SP & -- & IE - SP & TE \\
\hline 6 & $\mathrm{AP}-\mathrm{OC}-\mathrm{IE}-\mathrm{SP}$ & -- & TE -SP & -- & IE - SP & TE-SP \\
\hline 7 & $\mathrm{AP}-\mathrm{IE}-\mathrm{SP}-\mathrm{SD}-\mathrm{Y}$ & $\mathrm{AP}-\mathrm{IE}-\mathrm{NR}-\mathrm{SP}$ & -- & NR - SP & IE - SP & -- \\
\hline 8 & SP & $\mathrm{AP}-\mathrm{IE}-\mathrm{SP}$ & -- & SP & & \\
\hline 9 & $\mathrm{OC}-\mathrm{IE}-\mathrm{SP}$ & $\mathrm{OC}-\mathrm{IE}-\mathrm{SP}-\mathrm{GCT}$ & TE-SP & TE-SP & & \\
\hline 10 & $\mathrm{AP}-\mathrm{OC}-\mathrm{IE}-\mathrm{SP}$ & IE - SP & SP & TE-SP & & \\
\hline
\end{tabular}


Note: Academic Planning (AP), of the context (OC), Teacher's Explanation (TE), Answers the Students (AS), Involvement Encouragement (IE), Guidance (GU), Non-verbal Revision (NR), Students Participation (SP), Students' disruptions (SD), I. General comments from the teacher (GCT), Unobservable (Y).

However, the conduct Answers the Students (AS) produces several patterns. It is followed by Students Involvement (SI) in five of the UdG lecturers and eight from the ULL, pointing out that the student participates in the class teaching process. The next consequent conduct is Teacher's Explanation (TE), which appears in four lecturers from each university. This pattern seems to demonstrate a good rhythm in the sequencing of the class, since the lecturer resumes the explanation once he has answered the questions of the students.

In table number 4 we present the resultant patterns of the Encouragement Function. The code Reinforcement (RF) produces Teacher's Explanation (TE) in six of the ULL lecturers, in theoretical lessons and four of the practical lessons, as well as in five of the UdG. It manifests that, after the students' reinforcement, the lecturer keeps teaching the lesson.

Table 4. Antecedent Conducts to the Encouraging Function and Consequent Conducts in First Lag

\begin{tabular}{|c|c|c|c|c|c|c|}
\hline \multirow[b]{4}{*}{ Pr. } & \multicolumn{6}{|c|}{$\begin{array}{l}\text { ENCOURAGING FUNCTION } \\
\end{array}$} \\
\hline & \multicolumn{4}{|c|}{ ULL Lecturers } & \multicolumn{2}{|c|}{ UdG Lecturers } \\
\hline & \multicolumn{2}{|c|}{ RF } & \multicolumn{2}{|c|}{ IE } & \multirow[t]{2}{*}{ RF } & \multirow[t]{2}{*}{ IE } \\
\hline & Theoretical & Practical & Theoretical & Practical & & \\
\hline 1 & -- & $\mathrm{RF}$ & -- & $\mathrm{AT}$ & TE & AT \\
\hline 2 & TE & - & $\mathrm{SP}-\mathrm{AT}$ & -- & AP - TE & AT \\
\hline 3 & -- & -- & -- & AT & $\mathrm{TE}$ & AT \\
\hline 4 & -- & -- & AT & AT & -- & AT \\
\hline 5 & $\mathrm{TE}$ & $\mathrm{TE}$ & AT & AT & -- & AT \\
\hline 6 & TE & -- & AT & -- & -- & AT \\
\hline 7 & TE & -- & AT & AT & -- & AT \\
\hline 8 & -- & TE - IE & - & AT & & \\
\hline 9 & TE - IE & -- & AT & AT & & \\
\hline 10 & TE & TE - IE - NR & AT & AT & & \\
\hline
\end{tabular}

Note: Academic Planning (AP), Teacher's Explanation (TE), Reinforcement (RF), Involvement Encouragement (IE), Non-verbal Revision (NR), Students Participation (SP), Answers the teacher (AT).

The other code of this function, Involvement Encouragement (IE), produces a significant and common pattern in all the lecturers, for the consequent conduct that follows is Answers the Teacher (AT), which means the lecturer has achieved his goal gaining the involvement of the students.

The Control Function, which is made operative in the code Negative Possibility (NC) does not produce behavioral patterns. This conduct is not very frequent and it is non-existent in ten of the ULL lecturers, since the students presents not much disruptions, if there are any. In lecturers from the $\mathrm{UdG}$, three of seven lecturers give significant patterns. (Lecturer \#2 is followed by Academic Planning, Non-Verbal Revision or Student Involvement; in teacher \#3, Teacher's Explanation; in lecturer \#7, Academic Planning or Teacher's General Interactions). It is important to indicate the absence of students' disruptions. It supposes that the needed discipline to carry on with the classroom is present when teaching motivating contents and with a rhythm that avoids inappropriate behaviors.

The Advising Function (see table \#5) has as its main objective to teach the students how to develop a specific work. In the case of the ULL, this conduct does not occur in the theoretical classes, what is reasonable due to the type of behavior that it makes operative. Both conducts, Guidance and Non Verbal Revision, produce significant patterns in practical lessons from three of the lecturers, but they are low frequency conducts. 
Table 5. Antecedent Conducts to the Advising Function and Consequent Conducts in First Lag

\begin{tabular}{cccc}
\hline & \multicolumn{2}{c}{ ULL Lecturers (Practices) } & UdG Lecturers \\
\cline { 2 - 4 } Pr. & GU & NR & NR \\
$\mathbf{1}$ & TE & -- & -- \\
$\mathbf{2}$ & -- & -- & OC - SD - Y \\
$\mathbf{3}$ & -- & -- & -- \\
$\mathbf{4}$ & -- & -- & -- \\
$\mathbf{5}$ & $\mathrm{NR}$ & $\mathrm{GU}-\mathrm{Y}$ & $\mathrm{OC}-\mathrm{Y}$ \\
$\mathbf{7}$ & -- & -- & $\mathrm{OC}-\mathrm{SD}-\mathrm{Y}-\mathrm{X}$ \\
$\mathbf{8}$ & -- & $\mathrm{OC}-\mathrm{SP}-\mathrm{Y}$ & $\mathrm{RF}-\mathrm{SD}-\mathrm{X}$ \\
$\mathbf{9}$ & -- & -- & \\
$\mathbf{1 0}$ & $\mathrm{GU}-\mathrm{NR}$ & $\mathrm{RF}-\mathrm{GU}$ & \\
\hline
\end{tabular}

Note: of the context (OC), Teacher's Explanation (TE), Reinforcement (RF), Guidance(GU), Non - verbal Revision (NR), Students Participation (SP), Students' disruptions (SD), Other behaviors (X), Unobservable (Y).

While Guidance does not take place at the UdG, Non Verbal Revision (visually supervising the development of the students' work), it produces significant patterns in four of the lecturers, the most common conducts being: Teaching Context Organization and Students Disruptions, possibly explaining this pattern the fact that the lecturer moves through the classroom and it produces the relaxation of the students.

In terms of the students' interaction, in most of the classes of the ULL lecturers, Students Involvement (SI) generates on the side of lecturers Students Answers (SA), given also in less occasions Reinforcement (RF). Both patters prove a good teaching progress for they obtain the appropriate feedback from the students, also reinforcing this behavior. It is expected that it will be kept in the future.

Table 6. Antecedent Conducts to the Interaction Function and Consequent Conducts in First Lag. ULL Lecturers

\begin{tabular}{ccccc}
\hline & \multicolumn{4}{c}{ INTERACTION } \\
\cline { 2 - 5 } Pr. & Theoretical & Practical & Theoretical & Practical \\
\cline { 2 - 5 } $\mathbf{1}$ & -- & AS - RF & -- & AS \\
$\mathbf{2}$ & AS - RF & -- & -- & AS \\
$\mathbf{3}$ & AS & AS - RF & -- & -- \\
$\mathbf{4}$ & AS - RF & AS & AS - RF & AS -RF \\
$\mathbf{5}$ & AS & AS -RF - GU & RF & AS - RF \\
$\mathbf{6}$ & AS - RF & AS - IE & TE - AS - RF & AS - RF \\
$\mathbf{7}$ & -- & AS & -- & TE - RF - IE \\
$\mathbf{8}$ & AS & AS - RF & RF \\
$\mathbf{9}$ & AS & AS & TE - RF - IE & TE - RF \\
$\mathbf{1 0}$ & AS & AS - RF & RF & R
\end{tabular}

Note: Teacher's Explanation (TE), Answers the Student (AS), Reinforcement (RF), Students Participation (SP), Answers the Teacher (AT), Involvement Encouragement (IE), Guidance (GU), Unobservable (Y).

When the previous conduct is Answers the Teacher (AT), we obtain two patterns from the lecturers: Reinforcement (RF) in eight of them, and Answers the Student (AS) in six. In several moments the rhythm of the class is resumed whether with Teacher's Explanation (TE) or Involvement Encouragement (IE).

In non-appropriate interactions (which only occurred once during theoretical classes with lecturer \#7), there is a significant pattern that follows Students Disruptions (SD) which results in Negative Possibility (NP).

General interactions produce significant patterns only in the observed conduct of lecturer \#9, both in theories as practices, following Teacher's General Interactions (TGI). During theoretical classes Academic Planning and Teacher's Explanation, and during practical lessons Students' General Interactions and a pattern when this is an antecedent conduct, followed by Teacher's General Interactions (TGI). In lecturer number ten we also found the pattern Teacher's General Interactions - Student's General Interactions to be significant. This type of dialogue is 
interesting because it reduces the real content of the classes. Nevertheless, these are conducts of low frequency (a relative frequency between 0,01 and 0,04 ) and it coincides with very dynamic classes with a high number of registered events, so it does not seem relevant although it has generated a significant pattern.

In table number 7 we present the patterns that appear from antecedent conducts of teaching interactions at the UdG. In all the examples there is Students Involvement (SI), that generates Answers the Student (AS). Most of them (except lecturer number 4) reinforce this behavior. Both patters prove a good teaching progress since they obtain the appropriate feedback from the students, also reinforcing this behavior. It is expected that it will be kept in the future.

The conduct Answers the Teacher (AT) equally produces a significant pattern in the lecturers. In all cases it is followed by Involvement Encouragement (IE), being also frequent Reinforcement (RF) or Teacher's Explanation (TE), which indicates the students are encouraged to participate. Following the exposition is also appropriate since it allows following the rhythm of the class.

In those cases where disruptions occur (low frequency conducts), the pattern that follows is Negative Possibility(NP) from the lecturer, that is, verbal calls of attention.

In relation to general interactions, if there is not a pattern when they are produced by the students, they do appear when the lecturer produces this type of communication. It only takes place in three of the lecturers, producing a variety of consequent behaviors. As it is the case of the ULL, they are low frequency conducts $(0,04)$.

Table 7. Antecedent Conducts to the Interaction Function and Consequent Conducts in First Lag. UdG Lecturers

\begin{tabular}{ccccc}
\hline \multicolumn{5}{c}{ INTERACTION } \\
\hline Lecturer & SP & AT & SD & GCT \\
\hline $\mathbf{1}$ & TE - AS - RF - NR & TE - RF - IE & -- & -- \\
$\mathbf{2}$ & AS - RF & TE - RF - IE & NP & AP- X - Y \\
$\mathbf{3}$ & AS - RF- NR & IE & NP & OC - TE \\
$\mathbf{4}$ & AS & RF - IE & -- & -- \\
$\mathbf{5}$ & AS - RF - NR & TE - IE & -- & -- \\
$\mathbf{6}$ & AS - NR & TE - IE - AS & -- & OC - NR -X \\
$\mathbf{7}$ & TE - AS - RF - X & TE - IE & NP & GGS \\
\hline
\end{tabular}

Note: Academic Planning (AP), of the context (OC), Teacher's Explanation (TE), Answers the Student (AS), Reinforcement (RF), Involvement Encouragement (IE), Negative Possibility (NP), Non-verbal Revision (NR), Students Participation (SP), Answers the teacher (AT), Students' disruptions (SD), I. General comments from the teacher (GCT), II. General comments from the students (GCS), Other behaviors (X), Unobservable (Y).

Instrumental categories are useful when analyzing the continuous flow of behaviors. They include three codes Other Behaviors (X), Unobservable Conduct (Y) and Teacher Leaves the Classroom (Z). The second one, Unobservable Conduct (Y) is only necessary to keep the sequence, so it has not been interpreted. The other two categories are interesting from the point of view of the lecturer's behavior.

While the code Teacher Leaves the Classroom does not present a significant pattern in the lecturers of the ULL or $\mathrm{UdG}$, Other Behaviors $(\mathrm{X})$ is present in three of the UdG lecturers, lecturer 4 (were the relative frequency is very low, $0,02)$ carries on with the explanation and lecturers 6 and 7 are followed by Non Verbal Revision.

\section{Discussion}

The evaluation of the teacher performance is very important in order to determine the quality of teaching (Martinez, 2013), but it seems difficult to implement because it is necessary to use observational methodology, which is a rigorous procedure but it is demanding in efforts. Thus, it is crucial to provide the program evaluators in Education with measurement procedures so it is easier for them to develop this type of evaluation of the lecturers.

In this research it has been analyzed the behavior of the lecturer in a real situation while he or she is teaching, during the development of the work. The crossed validity implemented in two different teaching systems, affirms the applicability of the instrument in the used observational method.

Despite the differences in each educational system, the studied lecturers share more similarities than differences. A common behavioral pattern in all cases is Involvement Encouragement - Answers the Teacher, and it shows active and interactive classes when encouraging the students. 
In the second place, in all the studied cases, Teacher's Explanation produces a significant pattern that differs from each other. Nevertheless, they share a common consequent, Involvement Encouragement, which allows us to indicate the types of lecturers who have an important constructivist component. This encourages the involvement of the students in the development of the sessions and helps them to over-think reflex about the content of the explanation.

The advising conducts are not frequent in all the analyzed lecturers. At the UdG there are not significant patterns for the Guidance conduct, which only takes place in practical lessons and it does not occur with all the lecturers of the ULL. This manifests that there are separately practical activities at the ULL and in the frame of the integrated classroom at the UdG. The components of the procedure are not very abundant in any of the two universities. However, the appearance of Non Verbal Revisions is more frequent, but it is not a common pattern either.

An important part of the teacher performance is the good educational practices carried out by the teacher, that is, what they should do to promote a good quality of teaching and an appropriate learning. An important part of good educational practices is giving feedback by answering the questions of the students. In the studied lecturers we observed a significant pattern between the students' involvement and the answer given by the lecturer, so it is possible to confirm that all of them share a good educational practice. Furthermore, there is an interest in encouraging the student's involvement whether if the student intervenes by own initiative (Students' Involvement) as well as when the students answer the lecturer, as it can be seen when following these two conducts, practically, in all cases by reinforcement from the lecturer

The obtained results manifest how lecturers under assessment display an appropriate teaching performance. This aspect is not strange because all of them volunteered for this study. It may be pointed out that the teacher's profile can vary in lecturers with a mediocre or unsuitable professional performance. However, the academic institution will decide if it is necessary to establish an evaluation procedure. When the conduct is analyzed in detail, it allows a very specific analysis of the behavior which translates into the possibility of creating and applying improvement action plans.

\section{References}

Bakeman, R., \& Quera, V. (1996). Análisis de la interacción. Análisis Secuencial con SDIS y GSEQ. Madrid: Ra-Ma.

Blanco, A., Castellano, J., \& Hernández- Mendo, A. (2000). Generalizabilidad de las observaciones de la acción del juego en el fútbol. Psicothema, 12, 81-86.

Cadenas, M., Rodríguez, M., \& Díaz, M. (2012). Los equipos de entrenamiento: una muestra para el estudio de los sesgos en la fiabilidad entre parejas de observadores. Revista de Investigación y Divulgación en Psicología y Logopedia, 2(2), 41-46.

Cameron, C. E., Connor, C. M., \& Morrison, F. J. (2005). Effects of variation in teacher organization on classroom functioning. Journal of School Psychology, 43, 61-85.

Casanova, H. (1999). Educación Superior en América Latina: Políticas y Gobierno. Revista española de educación comparada, 5, 155-176.

Cronbach, L.J., Gleser, G.C., Nanda, H., \& Rajaratnam, N. (1972). The dependability of behavioral measurements: theory of generalizability for scores and profiles. New York: John Wiley and Sons.

Dede, S., \& Baskan, G. (2011). Theoretical basis of comparative education and suggestion of a model: Comparative education council in Turkish education system. Procedia Social and Behavioral Sciences, 15, 3536-3542. http://dx.doi.org/10.1016/j.sbspro.2011.04.331

Díaz Hernández, M. C. (2014). Protocolo de Observación de Funciones Docentes en Universidad: Un instrumento para la evaluación de la conducta del profesorado universitario. Doctoral Thesis. University of La Laguna. Soportes Audiovisuales e informáticos.

Good, T. L., Mulryan, C., \& McCaslin, M. (2006). Grouping for instruction in mathematics: A call for programmatic research on small-group processes. In D. Grouws (Ed.), Handbook of research on mathematics teaching and learning (pp. 165-196). New York: Macmillan.

Harber, C., \& Serf, J. (2006). Teacher education for a democratic society in England and South Africa. Teaching and Teacher Education, 22(8), 986-997.

Hernández-Jorge, C. (2005). Habilidades de comunicación para profesionales. Tenerife: ARTE: Comunicación 
visual.

Ingvarson, L., \& Kleinhenz, E. (2006). Standards for advanced teaching: A review of national and international developments. Australia: The Australian Institute for teaching and school Leadership.

Kember, D., \& Leung, D.Y.P. (2011). Disciplinary Differences in Student Ratings of Teaching Quality. Research in Higher Education, 52(3), 278-299. http://dx.doi.org/10.1007/s11162-010-9194-z.

Kilimci, S. (2009). Teacher Training in Some EU Countries and Turkey: How similar are they? Procedia Social and Behavioral Sciences, 1, 1975-1980.

Martínez, J. F. (2013). Combinación de las mediciones de la práctica y el desempeño docente: consideraciones técnicas y conceptuales para la evaluación docente. Pensamiento Educativo. Revista de Investigación Educacional Latinoamericana, 50(1), 4-20. http://dx.doi.org/10.7764/PEL.50.1.2013.2

Mateo, J., \& Martínez, F. (2008). La evaluación alternativa de los aprendizajes. Barcelona: Ed. Octaedro.

Milanowski, A., Heneman, H., \& Kimball, S (2011). Teaching Assessment for teacher human capital management: learning from the current state of the art. WCER Working paper. Retrieved from http://www.acer.wisc.edu/Publications/workingPapers/papers.php

Montero, J., \& Montero, J. (2011) (sin publicar). Augen, v. $\beta$. Software Programme Computer Business Solutions.

Patterson, G.R. (1982). Coercive family process. Eugene, OR: Castalia.

Rodríguez, M., Cadenas, M., \& Díaz, M. (2011). Estimación del tiempo de registro óptimo para la observación de las funciones docentes del profesor universitario. Revista de Investigación y Divulgación en Psicología y Logopedia, 1(1), 10-15.

Rodríguez-Naveiras, E. (2011). PROFUNDO: Un instrumento para la evaluación de proceso de un programa de altas capacidades. Doctoral Thesis. University of La Laguna. Soportes Audiovisuales e informáticos.

Sackett, G.P. (1979). The lag sequential analysis of contingency and complicity in behavioral interaction research. In J. Osofsky (Ed.), Handbook of infant development (pp. 623-649). New York: Wiley.

Vaillant, D. (2008). Algunos marcos referenciales para la evaluación del desempeño docente en América Latina. Revista Iberoamericana y Evaluación Educativa, 1(2), 7-22. Retrieved from http://www.rinace.net/rie/numeros/vol1-num2/art1.pdf

Vasquez-Rizo, F., \& Galabán-Coello, J. (2012). Evaluating Postgraduate teachers: variables and influencing factors. Educación y Educadores, 15(3), 445-460.

Young, J., Hall, C., \& Clarke, T. (2007). Challenges to university autonomy in initial teacher education programmes: the cases of England, Manitoba and British Columbia. Teaching and Teacher Education, 23(1), 81-93. 